\title{
PROTECTING THE POOR IN VIETNAM'S EMERGING MARKET ECONOMY
}

\author{
Dominique van de Walle*
}

June 1998

\begin{abstract}
Vietnam's transition to a market economy has stimulated strong growth. Continued broad-based growth will help raise living standards for most people. But many will continue to be poor and most will remain vulnerable to risk. Under the former command economy, lack of mobility ensured close community and family solidarity and households belonged to local cooperatives that provided for the welfare of their members. Developing a reliable and effective system of redistributive transfers and safety nets to replace these faltering institutions is an important part of the successful transition to a market economy. This paper uses Vietnam as a case study in rapidly assessing the strengths and weaknesses of an existing safety net. Data are taken to be weak; in particular, rigorous ex-post evaluations of the components of the existing safety net are not available in time to inform policy choices. So the aim is instead to provide a broad qualitative assessment, also pointing to key issues on which knowledge needs to improve. The paper offers a critical overview of existing public safety net programs and a description of the principal sources of household vulnerability and what is known about coping strategies. This is followed by an agenda for strengthening the design and implementation of the main safety net programs.
\end{abstract}

The author thanks Jennie Litvack, Nga Nguyen, Martin Ravallion, K. Subbarao and Dennis Rondinelli for their help and useful comments. A slightly different version of the paper appears as "Protecting the Poor in an Emerging Market Economy," in Litvack and Rondinelli, (Eds) Economic Transition and Social Change: Institution Building in Vietnam. Quorum Books: Westport, Ct., 1998. 


\section{INTRODUCTION}

All households see some fluctuation in their incomes over time. Many have access to consumption-smoothing devices such as savings and borrowing that allow them to maintain relatively stable living standards. But the poor tend to have fewer reserves beyond what is needed to survive lean periods during normal years and also less access to credit. An unfavorable turn of events, particularly an unexpected one or even a series of small shocks, can be catastrophic. Poor people's exposure to downside risk in their living standards can also bring adverse long-term consequences from the depletion of their productive assets at times of distress and the adoption of costly risk avoidance strategies. ${ }^{1}$

Vietnam is no exception. The country remains an agricultural economy with a large share of the population relying almost exclusively on family-run self-subsistence farms. Their incomes are subject to the vagaries of the weather, disease, and other unexpected events. Transition to a market economy has stimulated strong growth in many parts of the country since the late 1980s and continued broad-based growth will help raise living standards for most people. But the country is starting from an extremely low base with extensive poverty and underdeveloped institutional structures. Many people will continue to be poor and most will remain vulnerable to risk in the foreseeable future. Some people will be slower to respond to market incentives and others will face catastrophic shocks, including those who respond quickly to market incentives. Households also confront shifting levels of productivity and needs over their life cycle.

Many of these issues were of less concern under the former command economy where lack of mobility ensured close community and family solidarity and where households belonged 
to local cooperatives that provided for the welfare of their members. Developing safety nets and redistributive transfers to replace these faltering institutions is an important part of the successful transition to a market economy.

Government intervention is often recommended to help protect the poor from the consequences of adverse events. A reliable and effective system of safety nets can help to prevent greater impoverishment, social and political dislocation, famine, massive migration, assets divestment, and generally to preserve the productive potential of the local economy. There is also mounting empirical evidence that by enhancing the poor's ability to cope with risk, schemes which are usually considered short-term, stop-gap measures may have important longerterm impacts on productivity and efficiency. ${ }^{2}$ Achieving these goals can also contribute to political stability and income equity-both important concerns of the government of Vietnam. Sources of vulnerability will differ in their importance from one region to another (for example between rural and urban areas, and between mountainous and coastal areas) and for different groups of poor households. Expectations will also differ between poor areas and those that are better off. In order to succeed, programs will have to be adapted to local circumstances. Yet, this can create tensions with other national objectives, such as the aim to treat all Vietnamese fairly and equally no matter where they live.

Vietnam is improving its poverty alleviation and safety net programs, but much more must still be done to modify the design of existing programs and fill large gaps in the systems and resources needed to protect Vietnam's poor and vulnerable. One important need, for example, is dealing more effectively with community-level covariate shocks such as natural 
disasters that confront the whole community. In general, existing programs aim primarily to direct transfers to certain groups of the poor rather than to fill an insurance function.

A number of the salient features of the Vietnam case, as well as the concerns to which it gives rise, are found elsewhere, such as in other countries in South East Asia like Laos and Cambodia, and in many poor Sub-Saharan African countries. These include a poor population engaged primarily in agricultural pursuits in a risky environment; a lack of resources; large regional disparities in living standards and in local resources, and a tendency for these to be positively correlated; the need to adapt to a changing and modernizing economic system; and problems and horizontal inequalities arising out of a decentralized system of centrally mandated, locally administered programs. ${ }^{3}$

This paper uses Vietnam as a case study in rapidly assessing the strengths and weaknesses of an existing system of transfers and safety nets. Data are taken to be weak; in particular, rigorous ex-post evaluations of the components of the existing social security system are not available in time to inform policy choices. So the aim is instead to provide a broad qualitative assessment, also pointing to key issues on which knowledge needs to improve.

The paper provides a critical overview of the existing public poverty and safety net programs in Vietnam that aim to help and protect those outside the formal employment sectors, notably those in the rural economy and urban informal sector. It begins with a brief examination of the principal sources of vulnerability for Vietnamese households and what is known about household coping strategies. This is followed by a description of the various transfers and safety nets that are currently available to address low incomes and vulnerability for individuals outside 
the formal employment system and hence not covered by the government's social security benefits. Naturally, much of the focus is on rural households and individuals.

The paper draws on the author's numerous field visits to Vietnam, meetings with various Government ministries in Hanoi, and extensive discussions with provincial, district, and commune level peoples' committees and local government representatives. Additional insights come from the results of the 1992-1993 Vietnam Living Standards Survey (VNLSS)—a nationally representative, integrated household survey-and from other studies of living standards in Vietnam. Because rigorous evaluations have not been undertaken, little is known with certainty about the actual performance of existing programs. Hence, analysts can only speculate (informed by experience elsewhere) on their strengths and weaknesses in protecting the poor. The virtues and weaknesses of the government's flagship program—-the "Hunger Eradication and Poverty Reduction" Program (HEPR)—are highlighted and an agenda for strengthening the design and implementation of the main safety net and transfer programs is proposed.

\section{SOURCES OF VULNERABILITY AND COPING STRATEGIES}

The key to designing effective policies for social protection lies in first understanding the characteristics of the poor. As in many developing countries, poverty in Vietnam is a predominantly rural phenomenon. Close to 80 percent of Vietnam's population and 90 percent of the poor live in rural areas. The incidence of rural income poverty is 57 percent based on the cost-of-basic needs method using the 1993 Vietnam Living Standards (VNLSS) household survey data. ${ }^{4}$ 
Poverty in Vietnam has a distinctive regional dimension. The headcount index of rural poverty ranges from a low of 45 percent in the rural South East to a high of 74 percent in the North Central region. The South is in general less poor than the North and the coastal and mountainous areas of the Center. Poor regions, especially mountainous ones, tend to be the most disadvantaged in terms of infrastructure, remoteness from market and information centers, lack of water and water management, and deficits of food staples. Here markets are least developed. The majority of Vietnam's ethnic minorities, who experience some of the most severe poverty, inhabit remote mountainous regions.

The center's coastal regions tend to have high population densities but poor quality soils threatened by encroaching salinity and acid sulphate contamination. They suffer especially from frequent natural disasters such as typhoons and devastating floods, followed by serious bouts of drought. But other regions also experience water related hazards. It is estimated that close to three-quarters of the country's population is susceptible to flooding. ${ }^{5}$ Mountainous areas are prone to flash floods and landslides, while the low-lying river deltas often experience severe river flooding and typhoons. Moreover, analysis of trends over time suggests that the frequency and severity of natural catastrophes are on the rise as a result of environmental degradation. ${ }^{6}$

The rural household economy, and therefore poverty, is intrinsically related to agriculture. Agriculture is the primary occupation of 84 percent of all rural workers aged 6 years and older. ${ }^{7}$ The highest incidence of poverty is found among farmers. Poor households often have abundant potential labor supply relative to other factor endowments, but without outside employment opportunities, farm-productivity is driven down to low levels. The fundamental cause of poverty for these households is too little land and capital, or too little non-farm 
employment, for the number of able-bodied workers. In many parts of Vietnam, rural labor markets remain thin and underdeveloped. Widespread underemployment in agriculture coupled with seasonality in work and incomes makes poverty particularly acute in places where few annual cropping cycles are feasible because land or water is scarce.

Still other households are characterized by insufficient labor. They have less able-bodied family workers than they need to farm their land, usually because of the demographic or health circumstances of the family (the result of death, old age, illness, disability of the breadwinner, or the presence of many small children). Debilitating morbidity from infectious diseases such as malaria and iodine deficiency remains common. Vietnam also has more than its share of disabled due to the country's long history of recent wars.

Poor households typically lack either savings or access to credit. In Vietnam, as in most developing countries, a household's ability to invest in the land or diversify into off-farm activities depends largely on the availability of its own savings. Limited amounts of informal credit are available only at high rates of interest. The labor surplus thus results in low yields, in the inability to raise livestock or carry on with sideline activities outside agriculture, and in vulnerability to extreme seasonality of incomes and food insecurity.

In addition to a lack of physical capital, the lack of human capital-good health, skills and education-creates poverty, and is reinforced by it. Despite Vietnam's efforts to educate its entire population, many poor households cannot afford the out-of-pocket costs of schooling and children remain indispensable labor inputs for many families. Many ethnic minorities do not speak Vietnamese, and-particularly among poor households-have not been to school. As in education, Vietnam has achieved much in raising overall health status. However, child 
malnutrition rates have been extremely high, especially among the poor. The prevalence of stunting for 25 to 36 month old children in the poorest two deciles was estimated to be close to 70 percent in the 1992-93 VNLSS. Low birth weight was also found to be common among the poor. ${ }^{8}$

Isolation from information, trade and market networks, physical infrastructure, and market and institutional structures (credit, land and labor) tends to limit the opportunities for offfarm diversification and employment, and to worsen seasonality and income variability. These factors increase the vulnerability of poor households and weaken their ability to withstand shocks and smooth consumption adequately. The very same factors have prevented many households from participating in the benefits of market reforms. Meanwhile, many of the same households also suffered from some of the reforms in social sector and social welfare services provision brought on by the transition.

As in all poor rural agriculture-based economies, Vietnamese households face a variety of threats to the stability of their living standards. It is useful to distinguish between covariate and idiosyncratic, as well as unanticipated and anticipated sources of income variability. Fluctuations are said to be covariate when an entire community or region is simultaneously affected. Common examples in Vietnam include wars, severe floods, drought, typhoons, crop pest infestations, pre-harvest lean seasons and economic recession and changes in the terms of trade. Idiosyncratic shocks affect a single household or individual leaving others unaffected. The death of the family breadwinner or an illness are examples of idiosyncratic shocks that affect many households in Vietnam. 
Sources of vulnerability differ in importance from one region to another. ${ }^{9}$ For example, districts in the Central coastal region are extremely prone to destructive natural calamities. In addition, agricultural production is often hostage to 6 months of drought followed by floods. In the absence of improved water management, the poor suffer from food insufficiency during a good part of each year. In other regions, malaria and tuberculosis are common ailments that can temporarily ruin a household's livelihood.

Individuals and communities do take various steps to protect themselves from living standards variability, but it is important to understand the limitations of these arrangements. ${ }^{10}$ For example, in similar settings in rural Southwest China, it has been found that 40 percent of an income shock is typically passed on to current consumption for the poorest decile of the population. ${ }^{11}$ Covariate and unanticipated shocks are probably the hardest for the poor to cope with, either by their own means or with community support. Income fluctuations that occur as a result of ordinary seasonality or old age for example, are readily anticipated, and poor households have typically devised methods for coping with them. But the methods for dealing even with anticipated variability do not always work well and may have costs in terms of average living standards. Unanticipated shocks, such as sudden illness or a crop failure, often have adverse consequences in both the short and long terms and poor households can do little to protect themselves against them.

Community and other private arrangements provide some degree of security to many households. For example, Vietnamese farm households typically adopt production strategies that help to minimize both their vulnerability to natural hazards and the impacts of disasters. But 
there is evidence that such strategies-with costs to average incomes-coupled with frequent occurrences of natural disasters in certain regions, are helping to widen regional inequalities. ${ }^{12}$

As reflected in the Vietnamese idiom "the intact leaf covers the ragged one," various informal and quasi-market community-level arrangements are used to help families; for example, the mass organizations may arrange to have someone else work the land for a family whose breadwinner is transiently ill. Informal arrangements might also be made to (in effect) hire labor in, or rent land out. Exchanging labor time among households, particularly to cope with seasonal or unexpected labor shortages, is a time honored tradition in Vietnam. ${ }^{13}$

The extended family remains important in Vietnamese culture, which has a strong Confucian heritage. An analysis of the VNLSS reveals that a large share of Vietnamese households either received (44 percent) or gave (46 percent) private transfers to other households. ${ }^{14}$ In general, transfers flow from the young to the old. Such private forms of insurance tend to be more effective and reliable for some among the vulnerable in certain circumstances, but they are often not available to the poorest among the poor and they don't cope well with covariate risk and unanticipated shocks. They need to be complemented by effective public programs.

Finally, it is important to note that some informal social protection schemes also exist in various parts of the country, set up by farmers or other interest groups or whole communities. ${ }^{15}$ Members make regular contributions and can expect to get insurance benefits in emergencies and for old-age. However, little is known about how extensive or how well such schemes perform in providing risk insurance to their members. 


\section{AN OVERVIEW OF EXISTING PUBLIC PROGRAMS}

A strong and pervasive view in government and in mass organizations is that the responsibility for poverty alleviation must be shared across three key groups: government, the community, and poor people. Problems cannot be solved by government alone; it can act as the catalyst to mobilize resources at the local level, but the community and the poor must bear some of the responsibility. These perspectives are likely to be influenced and conditioned by severe budget constraints. For, while there is clearly a conviction that government has a role in ensuring equity and that market mechanisms lead directly to distributional inadequacies, budgetary resources to deal with these problems are limited. Thus, a large number of initiatives and programs exist or are planned even though resources are not commensurate to government aspirations. Poverty-related policy promulgations abound, but implementation and coverage relies primarily on local authorities and resources, which are rarely adequate. One result is enormous variance across provinces in assistance to the poor and vulnerable. Another is an overwhelming emphasis on credit for income-generating activities as the way to help the poor help themselves and graduate from poverty.

In 1997, the public social safety net essentially consisted of five programs:

1. The Social Guarantee Fund for Veterans and War Invalids provides compensation for those who contributed to the war effort or suffered from the war;

2. The Social Guarantee Fund for Regular Relief gives assistance to those who are not able-bodied or able to partake in productive activities including the disabled, orphans, and the elderly; 
3. The Contingency Fund for Pre-Harvest Starvation and Natural Disasters provides contingency relief to address pain caused by natural disasters and lean season starvation;

4. The National Development Programs (14 national development programs) are to some degree related to promoting growth and reducing poverty mainly by providing credit for income generation at concessional rates and building infrastructure for those households who are held back by poor physical infrastructure and lack of capital.

5. The Social Security System consisting of employment-related social insurance for formal sector workers.

During 1998 many of these programs (except Social Security) were consolidated into one national poverty program-the "Hunger Elimination and Poverty Reduction" Program (HEPR)-in order to better mobilize and coordinate antipoverty resources.

\section{The Social Guarantee Fund for Veterans and War Invalids}

Centrally funded programs of the Ministry of Labor, Invalids and Social Affairs (MOLISA) address the consequences of Vietnam's recent wars by helping victims and others who contributed to the national liberation struggle. Only those who backed the winning side are potentially recognized as victims or worthy of the country's gratitude. Programs provide assistance for handicapped war veterans, resistance fighters and others who aided the war effort, and help to the families of fallen soldiers. New schemes, often planned a long time before the necessary budgets become available, are periodically announced and lists of qualifying 
individuals are prepared at the commune level. For example, a 1994 decree honors heroic mothers: women who lost an only child or more than 3 family members including their husbands in the 1954-1975 wars. By May 1996, the "heroic mother" title had been conferred on 37,000 women. A subsequent check of the records found, however, that 2,577 of one round of 2,842 nominees were already deceased.

Since the last ordinance announced in 1994, the number of beneficiaries from these programs has risen to nearly 2.4 million. ${ }^{16}$ Those who qualify under most of the sub-categories in principle receive cash transfers on a monthly basis. Each individual is allotted the same amount from the budget. However, because the provinces are required to contribute, total amounts may differ from one place to another. A few other benefits may also be available including funeral fees and aid to one's family at death, medical insurance, waivers for children's school fees and preferential access to scholarships, land or housing assistance, and livelihood support. In other cases (such as in the heroic mothers decree), a one-time lump-sum is provided to help the household set up a future livelihood. Spending under "Veterans and War Invalids" is also allocated to building war memorials and centers for the disabled and providing wheelchairs and artificial limbs for amputees. Each responsible local authority is expected to make requests for such expenditures to MOLISA and to keep updated lists of subsidy-deserving veterans and war invalids.

Whether or not these subsidies will continue to be given to the families of deceased war veterans is likely to depend on the budget. Some war victims-such as agent-orange affected children-continue to be born. There is no set policy and periodic changes are likely. 


\section{The Social Guarantee Fund for Regular Relief}

The Social Guarantee Fund for Regular Relief aims at helping those-such as orphans, the disabled, the insane, and the elderly without family support-who for reasons unconnected with the wars are unable to support themselves. They are divided into two groups: those who are able to go about their day to day lives with support from the community, and those who cannot. A monthly stipend of VND 24,000, often given in the form of rice (10-12 kg), is stipulated for the first group, while placement into specialized provincial care centers and a monthly allowance of VND 96,000 is available for the others. In 1995, 195 social relief centers existed nationwide.

Commune and district officials are responsible for implementation. They compile lists of people who qualify for regular relief according to norms dictated by the Center. For example, to qualify because of disability, one must be unable to walk and have lost a large part of one's work capacity. How much, and how exactly this is defined, may well depend on available budgets. Each province sends it's approved list to the central government. MOLISA, the Ministry of Finance (MOF), and the Ministry for Planning and Investment (MPI) each review the requests and make recommendations to the national assembly for a final decision. Recommendations and decisions on transfers are based on various considerations including the numbers on the provincial lists, the population size and total budget expenditures of the province, and its geographical classification (mountainous, delta, etc). The ministries place different weights on different criteria and are known to disagree in their recommendations.

In addition to providing subsidies to the target groups, regular relief transfers from the central budget can be used to cover the costs of building, maintaining, administering, and equipping the centers, and of the rehabilitation, training and job placement of invalids. Whether 
the transferred funds make allowance for these expenditures or are based only on numbers of qualifying individuals times the subsidy allotted for each is not clear.

Labor departments at the district and commune levels are in charge of distributing transferred funds from provincial budgets to individuals. Central transfers do not appear to be sufficient to cover all those on the lists. Officials emphasize the need to be strict about who qualifies and to rely on contributions from the community. A fair amount of doubt was expressed in interviews about the reliability of provincial lists. MOLISA has supervision missions to the provinces to check lists, and try to reduce them. By their criteria, more people are placed on the lists than deserve to be. Communities are not usually able to mobilize much and so either the lists or the amounts must be reduced. It is not known exactly what happens then at the district and commune levels.

In reality, coverage of the target groups is far from complete. MOLISA figures for 1993 indicated that, nationwide, only 10 percent of orphans, 21 percent of the "lonely" elderly, and 5 percent of the disabled population actually received program benefits. ${ }^{17}$ In addition, tremendous variance is evident across regions both in numbers and in the share of the eligible who are covered. How these figures, and in particular the denominator, were defined is unknown. One explanation for the exceedingly low coverage is MOLISA's more generous criteria versus the national assembly's final appropriations. The low coverage may also reflect the public budget constraint-although that cannot explain the variance across regions-or the fact that take-up may be low and varies due to different local program stipulations. Another possibility is that the poor coverage of this program reflects some substitutability with local forms of assistance. 
The monitoring of how much money actually goes to those on the lists is also weak and is reflected in complaints from the grassroots to the central government and in numerous corruption scandals. Some of the problems arise from infrequent reevaluation of the lists. For example, a beneficiary may move to another province, register with his or her new locality's Labor Department, and be granted a new certificate. The Labor Department in the old province has an incentive to leave the person on the rolls for as long as possible. Laxity in checking for this kind of duplication reinforces powerful incentives for maximizing the number of names on the lists.

\section{The Contingency Fund for Pre-harvest Starvation and Natural Disasters}

For a long time, the Government of Vietnam has helped localities deal with the consequences of catastrophic events such as natural disasters and difficult pre-harvest periods. In the past when a natural calamity occurred, MOLISA would dispatch a team to assess the damage and discuss the situation and estimated level of required help before a final decision on aid was taken. This process tended to take a long time. It order to expedite it, the government began in 1994 to encourage each province to set up a relief or "Contingency" Fund (CF) for dispensing emergency relief and starvation relief for natural disasters and inter-crop hungry periods. This small fund is not meant to fully cover needs but rather to provide a reserve that allows the provinces to move quickly in an emergency. When more is needed, the province is expected to mobilize local contributions, and can also make a special request from the central government. Roughly 60 percent of provinces make proposals for additional funds each year. MOLISA reviews the requests and funds about 30 percent. Use of the money is largely at the discretion of 
the province, although the Center provides guidelines. Each province's Department of Labor oversees the funds and allocates them directly to people in affected districts.

\section{National Development Programs}

Fourteen national development programs are classified as poverty programs that target areas of national priority. Many of these only indirectly impact poverty alleviation, although some of their components are poverty-oriented. Taken as a whole, these programs represent an important source of funding for communes-estimated at 27 percent of average commune level non-salary recurrent costs by one source. ${ }^{18}$ To some degree, the programs also redistribute resources to poorer provinces. The National Programs encompass reforestation and coastal reforestation; job creation; provision of credit; family planning; health care, disease control, and education programs; and support to minority and ethnic groups and mountainous areas. The funds for these programs come from the budget and from grants or preferential loans from international organizations.

Two of the larger programs-Program 120 (employment promotion) and Program 327 (reclamation of barren hills and waste land and settlement of ethnic minorities)-are considered important in poverty alleviation. Both have large credit components. Initially, much of the effort and resources of Program 120 were focused on labor restructuring and retraining laid-off state enterprise employees. Over time, an increasing share of the funds have gone to "credit for employment creation" with local peoples' committees and mass organizations in charge of dispensing loans. In 1995, 80 percent of the program's funds went to providing subsidized credit. Program 327 is also geared to financing loans, primarily for sustainable agriculture and forestry 
management projects. Twenty other sub-programs are also directed at providing preferential credit to the households. Much of the rest of program 327's budget is devoted to developing complementary infrastructure in new settlement areas. Reviews of the National Programs conclude that there is considerable room for improvement in cost-effectiveness. Shortcomings can largely be blamed on the Center's inadequate control and monitoring of within-province budgetary allocations and the selection of projects and loan recipients. ${ }^{19}$

\section{Consolidation Under a National Hunger Elimination and Poverty Reduction Program}

In 1996 the government proposed a national hunger elimination and poverty reduction (HEPR) program to coordinate existing and new efforts, as well as the resources for combating poverty. The impetus for the national HEPR arose out of the growing recognition of drawbacks in the country's current approach to poverty alleviation. These include: 1) the lack of integration between existing programs leading to a lack of coordination between policies and a diffusion of resources; 2) the heavy emphasis on credit and relative neglect of education, training, health care and infrastructure development; 3) the lack of national poverty standards; and 4) lack of an effective mobilization of the community behind the poverty reduction efforts.

The national program takes its cue in part from the provinces. Following the lead of Ho Chi Minh City in the early 1990's, 44 provinces set up HEPR Funds as a way of coordinating (local and central) activities, resource mobilization, and spending. Again, most of the funds' activities have centered on granting loans with preferential interest rates to help individuals set up businesses. Considerable variance has continued to exist across provinces both in who gets assistance and how they are assisted because the selection of beneficiaries has only been partly 
determined by the central government's stipulations and guidelines and because of differences in local capacity to supplement central funds. The government responded by drawing up plans for better coordination of activities and standardization of norms across localities by means of a national umbrella HEPR program.

The national program intends to provide an integrated policy and planning framework and coordinate efforts across different sectors and ministries. For example, the National Programs and other sectoral sub-programs (such as run by the Health or Education Ministries) that were directed at the poor have now been incorporated into the HEPR. A few additional programs are also planned including: jobs for the disabled; help for agent-orange affected children; and help for the elderly without family support. The national program subsumes regular relief that previously targeted these groups but was only able to meet part of their needs. HEPR activities to help poor households in the period 1998 to 2000 include:

1. Land and production policies for the poor. The government estimates that close to 6 percent of farming households now live in poverty due to a lack of land. Efforts will be made to redistribute unused or inappropriately distributed commune land, or to move willing households to new economic zones. Provincial and district governments are responsible for ensuring that all households are adequately endowed with land.

2. Micro-credit for income-generation at concessional rates. Approximately 30 percent of poor households have already been provided with credit from various sources. However, the poorest households were often denied access to these loans. The goal is for 90 to 95 percent of households identified as poor to have unconditional access to loans to improve 
their production. Responsibility for providing financial services to the poor lies with the newly established Bank for the Poor.

\section{Vocational training and technology transfer for poor households and their}

children. Voluntary groups will be dispatched to help the poor with business undertakings and technology transfer in production activities in poverty areas. Scholarships and other education stipends are planned for talented children from poor households.

4. Infrastructure in poor communes. A survey by the Ministry of Construction identified 1,160 out of 10,000 communes as suffering particularly acutely from a lack of infrastructure. The HEPR program plans to develop infrastructure in these communes, focusing on roads, electricity, safe water supply, primary and secondary schools, health care centers and communal market places.

5. Education and health care for the poor. Programs are planned for extending fee exemptions for poor children in primary and secondary school along with help with textbooks and other supplies, and possibly stipends for the extremely poor. Financial incentives will be given in view of filling teaching posts in remote mountainous areas. Similarly, fee exemptions will be extended for health care. Other programs in the health care area-population and family planning, malaria, goiter, immunization-will also be coordinated through the HEPR.

6. Support for the disabled and elderly poor, and for victims of natural disasters. HEPR will aim to help all the poor without a capacity to support themselves. Free health care and other support enabling participation in the community will be provided. One million poor disabled individuals are expected to be targeted through this program. The HEPR program also controls a special fund for helping those who are affected by natural disasters. 
7. Other initiatives. A number of other schemes targeted to women and ethnic minorities, and aimed at promoting employment (including through public works schemes and subsidized micro-credit), and protecting the environment, also fall under the HEPR umbrella.

The government estimates that about VND 10,000 billion or close to US\$1 billion are needed to achieve these objectives over the 1998 to 2000 period. About one third of the funding is projected to come from the central government budget; 4 percent from local government budgets; the largest amount, 43 or so percent of the total, is to be mobilized through mandatory (37.5 percent) and voluntary (5.8 percent) local contributions; while the rest will come from international organizations and through integration with central and local socio-economic programs. ${ }^{20}$ Much of the money will be distributed to provinces through a variety of financing methods such as loans and grants. Provided this target is achieved, the government predicts that hungry households will be a thing of the past while poor households will decline from 17.7 percent in 1998 to 10 percent by the year 2000. Funding will be allocated primarily to infrastructure building (38 percent of the total budget), the provision of credit (27 percent), and resettlement (12 percent). ${ }^{21}$

HEPR documents also emphasize greater decentralization of implementation and active national participation. Activities include awareness campaigns to motivate solidarity and mobilize charitable contributions and other forms of participation from the population. The government promotes HEPR as a "national endeavor" in the revolutionary tradition of Ho Chi Minh to eliminate hunger and raise the living standards of millions of Vietnamese. Much of this rhetoric reflects the government's political commitment to raising living standards for all, a widespread societal concern with rising inequity, and the reality of tight budget constraints. 
The program was approved by the national assembly and an Executive Board established in April 1998. Surveys will now be conducted to establish a registry of poor households at the commune level. Each identified poor household will then be given a book that certifies their status. This will be valid for as long as they are poor. Local authorities will check this yearly. Possession of this book then qualifies the household for loans, training, fee exemptions, and so on. Without the book, households can not participate in the programs. Other programs will continue, although it is not clear in what capacity.

\section{CHALLENGES FOR IMPROVING VIETNAM'S SAFETY NET}

Reforms of the current poverty alleviation and safety net system as embodied by the national HEPR do not propose a change in policy focus. The identified policy areas have all been emphasized in the past and were addressed by some of the larger programs discussed earlier, as well as through a variety of $a d$ hoc schemes. In terms of funding and priorities, it is clear that the primary focus of HEPR is micro-finance and infrastructure development. Whether or not it will reach the poorest, address all sources of vulnerability, and attack them in the most cost-effective manner is open to debate, but answers are not readily available. Judgements about the adequacy of existing policies must await, and be based on, careful evaluations. The potential immediate significance of the HEPR lies in the possibility of greater consistency in priorities and norms, better monitoring of outcomes, much needed integration and coordination between programs, better coverage of the poor, and redistribution towards poorer and less administratively capable provinces. 


\section{National standards}

The HEPR aims to help the hungry and very poor. MOLISA has been responsible for the criteria used to determine who and how many are hungry and poor in different regions. Since the period of high inflation in the 1980 s the government expresses poverty criteria in rice equivalents at local prices. The national criteria define the "starving" as those with the income per capita equivalent of less than $13 \mathrm{~kg}$ of rice per month in rural areas and $15 \mathrm{~kg}$ in urban areas; and "the poor" as those with less than $25 \mathrm{~kg}$ in urban areas, $20 \mathrm{~kg}$ in rural delta and midland areas, and 15 $\mathrm{kg}$ in rural mountainous areas. Based on these criteria, MOLISA estimated that in 19974.1 percent of all households (598,746 households) were starving and 16.2 percent were poor (2,347,133 households).

These are general criteria for the country, which have in theory been used to identify beneficiaries of transfer and safety net programs. In practice, they can and are altered to take specific province characteristics into consideration. Provinces currently enforce the principle of "relative standards" whereby the wealthier provinces establish higher criteria to allow for the fact that the average of everyone is higher though poverty still exists. For example, the Mekong delta with relatively high incomes, uses a locally more acceptable income equivalent of $30 \mathrm{~kg}$. Poverty cut-off points are also influenced by available resources. For example, Ho Chi Minh City's poverty standards are much higher than those proposed by MOLISA. In 1992, this was US $\$ 50 / y r / p e r$ cap in rural areas, US\$100 in urban areas. Since then, the line appears to have been raised as often as yearly—not to cover cost of living increases but because resources have grown. As of January 1996, it had been raised to $\$ 200$ for rural areas and $\$ 250$ in urban areas. 
Yet the number of poor households has not changed. Relative poverty considerations appear to have considerable influence on allocations.

Since different standards of "poverty" are used in different places, there will be uneven coverage and leakage. The poorest in Vietnam often need to rely on charity from the community. But they often live in poor communities in poor areas, where other households have little to spare. Coverage among Vietnam's poor appears likely to be quite uneven spatially, with poor people living in poor areas faring much worse than poor people in well-off areas. Of course, higher poverty lines do not imply that more of the poor are covered or that all below the line are covered. Indeed, a higher poverty line may simply allow more of those higher up on the income scale to be covered. There is a role for a central authority such as the national government to establish and enforce a national minimum standard below which none is allowed to fall. This is then an important determinant, along with information on local resources, of central transfer allocations to the regions earmarked for distribution to the poor.

The HEPR provides the institutional means for standardizing poverty lines and ensuring consistency of poverty comparisons and hence policy across provinces. Ideally, this will involve some rethinking of current definitions of absolute poverty and the establishment of a national consensus on minimum norms. For example, the current criteria need to better allow for spatial cost of living differences and varying levels of access to public and publicly-provided private goods.

\section{How much decentralization is optimal?}


As in the past, under the current system the poor are identified at the local level, by the commune chairman and mass organizations such as the women's union, the veterans group, and farmers' associations. These local authorities decide who qualifies for programs and dispense aid, including micro-credit. There appears to be little checking of the outcomes of this process and the scant evidence there is suggests that provincial lists of poor are not reliable.

There are clear advantages to relying on local knowledge. The chairman and mass organizations are likely to know commune households intimately and to be able to detect changes in levels of living standards over time. But there may be drawbacks as well. Even when national criteria are established, incentives are for localities to stack the lists of qualifying individuals in order to maximize transfers. Bias may occur from the preferences and agendas of those-including the commune chairman and mass organizations-who determine the lists at the local level. It is presumably in the interests of the women's union, busy aggressively campaigning for family planning, for example, to favor households practicing family planning in its' distribution of concessional loans for poverty reduction. The local authorities are often very powerful, and political favoritism and other abuse of power almost certainly leads to biases on the lists. ${ }^{22}$

Increasing mobility of households also poses new challenges. It is likely that many of the poor will benefit from migration (although the poorest may not have the skills, or be able to afford to move). Mobility is likely to help in cases of covariate risk, but not in dealing with idiosyncratic risk. Indeed, increasing mobility within Vietnam is likely to create problems with the current system of poverty relief. The system is based heavily on local targeting in communities where everyone knows everyone and what their income sources and resources are. 
With mobility, it is clearly more difficult to know who is really poor and avoid problems of adverse selection and moral hazard. Mass organizations are more inclined to favor households who are more permanent and likely to reciprocate in the future. Unless households are registered residents, the local authorities can simply ignore them. There is increasing seasonal and permanent migration to cities as well as other non-urban areas. Ho Chi Minh City had an estimated 1 million unregistered people in 1996. Workers come from far away provinces and because many criteria exist for becoming a registered and legal resident, they stay unregistered and without any kind of social security. Many jobs require official registration as do schools, health care facilities and other public services. Errors in identifying the poor are inevitable, and this problem is likely to increase.

The current social security system may also impede mobility. It could have large efficiency costs if the threat of less community assistance and loss of safety net benefits dissuades households from moving. ${ }^{23}$ A highly decentralized, community-based safety-net may well create spatial poverty traps. Evidence of such poverty traps has been found in Southern China in areas across the border from Vietnam. ${ }^{24}$ However, little is known about what role the institutional arrangements for social protection might play in fostering the conditions for spatial poverty traps.

In the future, local authorities and the mass organizations should have less discretion in defining who is poor. The advantages of decentralization come at a disadvantage of horizontal inequity. There is a clear tension here that the government must consider in designing the HEPR. One way to deal with this issue is by redistributing and ensuring correct allocations across areas based on standardized information about needs, performance, and outcomes. This 
requires a highly disaggregated national data base on indicators of living standards that is comparable over time and updated frequently. The collection of panel data-which follows the same households and communities over time-can be used to test and monitor the performance of interventions. Provided panel data exist, models are available for evaluating how well the safety net performs dynamically including how well it protects against poverty distinguished from how well it promotes out of poverty. ${ }^{25}$ Information on who the poor are and monitoring of who makes claims, who receives benefits, levels of social relief disbursements and outcomes needs to be strengthened. Attention must be given to the design of rules for implementation at the local level, taking account of incentive effects while exploiting the greater capacity of local communities to know who is poor. The rules should be standardized nationally. In addition, criteria for eligibility should be transparent and widely publicized. Making the lists of selected beneficiaries public may then help to overcome political maneuvering.

With increasing mobility in the future, the capacity for local areas to make these decisions will likely diminish. New pressures will be put on the Center to allocate according to non-geographic characteristics. Although geographical effects on poverty will remain important, the ability to achieve national objectives through local intervention will diminish because of mobility. However, this could still be a long way off. In the meantime, responses should aim to reduce the costs of migration and make registration simpler. High costs of migration are probably not in the interest of the poor nationally.

Once well-defined rules for delineating recipients have been instituted for all programs and regions, it will be easier to coordinate between programs and integrate objectives so as to maximize the impact and coverage of resources. The criteria for allocating relief across 
provinces remains haphazard. Each program is subject to different rules and many are implemented by different ministries. Outcomes are unlikely to be optimal from the point of view of reducing poverty. Methods used for determining provincial needs and transfer amounts need to be standardized across ministries or the responsibility relegated to a specific ministry.

Implementing an integrated, national safety net will probably entail greater spatial redistribution. Resources are extremely limited. One objective of poverty and safety net program proponents must be to increase budget allocations for promoting and protecting the poor. Another equally important and perhaps more feasible option in the short term is to ensure that the little there is goes to the neediest households. There are currently clear gaps in coverage. Vulnerable households in poor areas are less well served than others by the existing arrangements. The national HEPR also provides hope for provinces worst hit by natural calamities and most prone to a hungry lean season. The institutionalization of workable national norms and better monitoring systems will help towards ensuring a distribution of resources which aims to better equalize the ability of provinces to help their poor. Political resistance from better off provinces can be anticipated. It will help if all Vietnamese understand well the objectives of a safety net.

\section{Covariate Risk}

The Contingency Fund (CF) appears to have been the only one of Vietnam's poverty alleviation and safety net programs specifically aimed at providing insurance against covariate risk. As recognized by the government, natural disasters are an important source of vulnerability and impoverishment for many households in Vietnam. Although a complete accounting of the 
economic and social impacts of natural disasters is difficult, some statistics help put into perspective the degree of devastation that is wrought. Official numbers record the number of lives lost between 1980 and 1994 due to floods and typhoons alone at 6,862. The annual losses resulting from floods in the Red River and Central Coast regions is estimated to be around US $\$ 130$ million. ${ }^{26}$ Nevertheless, none of the initiatives under the HEPR specifically aims at reducing that vulnerability or mitigating the socio-economic impacts of natural hazards. ${ }^{27}$ Indeed, there is much the government could do to strengthen disaster preparedness, warning systems, prevention and mitigation systems. ${ }^{28}$

On its own, the $\mathrm{CF}$, or the fund that has replaced it, can only help minimize the deleterious effects of shocks by introducing flexibility and establishing greater capacity to respond quickly. However, little is known about its actual performance in protecting the poor. Once again, it seems that a large part of the funds are mobilized locally with only moderate input from the center. Furthermore, the evidence suggests that although post-disaster relief is usually forthcoming, funding for rehabilitation and reconstruction is rarer. ${ }^{29}$ Yet, it is also true that the poorest provinces tend to experience some of the most devastating and frequent natural disasters. Poverty is likely to increase in depth and severity if aid amounts are not sufficient for full recovery from shocks. If communes and households with already low reserves are left worse off and responsible for longer term rebuilding, many are likely to fall into a chronic state of impoverishment following natural catastrophes. As mentioned above, this is also likely to worsen regional disparities. The system should be better geared to preventing this from happening. This is an area where the central government is best positioned to take on the crucial role of pooling risk and redistributing assistance to poorer provinces when the need arises. The present 
financing arrangements are probably too decentralized to obtain the most out of risk-sharing nationally. The capacity to respond efficiently to disasters requires flexible budgets that can adapt to yearly variance in the severity and frequency of shocks. Given the reality of limited budgets, the system should also be designed to give priority to the poorest regions and households within them. Poor provinces should get relatively more, holding shocks and population size constant. This program is a key candidate for generous funding. Before channeling resources to it, however, a thorough evaluation of the existing program is warranted.

Some thought should also go to devising a separate policy instrument for pre-harvest starvation. This source of vulnerability is fundamentally different in that it can usually be anticipated. With time and money, some damage prevention will become feasible for both types of shock. Improved irrigation facilities, technological innovation, well-functioning labor markets, diversification of income sources and higher living standards generally should eventually conquer the hungry season for most households. Better construction and building materials, protective sea dikes, water management networks, the introduction of more resistant crop strains and early warning systems should also work to attenuate damage from natural disasters in the longer term. However, natural disasters will forever periodically and unexpectedly occur. A flexible buffer stock of food or cash is a reasonable response to such an eventuality.

It may also be more cost-effective to stabilize consumption through lean seasons with different instruments. In particular, the potential for self-targeted public works schemes should be explored because they have been useful in preventing famines and sustaining poor households 
through lean periods in many countries. ${ }^{30}$ They can serve an important insurance function by reducing the uncertainty faced by the poor that can arise due to uninsurable variability in their incomes. The schemes typically provide unskilled manual work on small-scale rural public works projects, employing people who may have temporarily lost their income earning sources. If they are well designed, the advantage of such programs is that they are self-targeted in that the choice of whether to participate is left to individuals, and the schemes can achieve a rapid response to an impending collapse in living standards. Providing employment following a shock may not be appropriate. In general, for this to work there needs to be scope for unskilled labor intensive rural infrastructure projects in the region; it must be possible to strategically set the wage level; and the budget and project implementation must have the flexibility to adapt to sometimes rapid changes in the need for the schemes.

\section{What's Missing?}

A complete safety net should protect the poor from risk as well as help promote them out of poverty. The majority of Vietnam's poverty alleviation and safety net policy interventions are geared to promotion rather than providing insurance against risk. Although many policies can be thought of as serving both functions, the system appears on the whole to be poorly geared towards helping individuals who are hit by idiosyncratic shocks. Protection from covariate shocks may not be functioning particularly well either, but recognition of the problem, and institutions for addressing it do exist, as discussed above. Individuals and households subject to an unexpected idiosyncratic shock must rely on their own reserves, family, friends and 
community solidarity. This is a large gap in the current system to which some attention should be given.

Another area of potential concern relates to the interhousehold distribution of welfare. The focus of official poverty measurement and policy tends to be the household. Policy design implicitly relies on the redistributive potential of institutions such as the family and community. This may at times fail women and children. To assume equitable treatment within the household may not be wise from the point of view of poverty reduction now or in the future. For example, there is much evidence of severe child malnutrition in Vietnam. And research has demonstrated the irreversible damage that childhood malnutrition can cause. Other than school fee exemptions, there appear to be relatively few attempts on the part of the government to specifically target children. This may in part be due to the fact that international NGOs have often taken on this role and specialized in child nutrition projects. However, more efforts need to be made to protect children from poverty and its lifelong deleterious consequences.

\section{Mobilizing Resources}

More resources are needed for some types of interventions and will require even higher taxation and some reallocation across programs. Both options present difficulties. Households are taxed-explicitly or otherwise-in a large number of ways in Vietnam. ${ }^{31}$ In rural areas, they are expected to provide up to 10 days of labor per person to build and maintain local infrastructure. Additional "contributions" are constantly being mobilized for one cause or the other. Very little is known about the distribution of the burden of these taxes and how this varies among provinces. The existing system may also impose high marginal tax rates on poor people. 
Households are removed from "lists of the poor" if they do too well. There will be powerful incentives to remain on the registry of poor households. How are such "poverty traps" avoided? Are there costs to participation such as stigma that limit the problem? Do the local authorities monitor work effort and how well? This too will become more difficult with increased mobility.

Freeing up resources by cutting and reallocating funds faces political hurdles. Some current expensive programs have strong political support. For example, questions could be raised about public spending for war veterans and invalids. First, more needs to be known about the living standards of the beneficiaries. Not all of these households are likely to be poor or unable to support themselves. The present system provides pecuniary benefits and bestows honorary benefits. The latter may be politically necessary but relatively cheap. It could also provide the basis for introducing an element of targeting whereby transfers would go primarily to the needy among those on the lists and medals to the less needy. Of course, this would require a method for correctly identifying the poor.

The political and economic realities would also have to be carefully examined. These programs and the political and societal will to support them have become sacrosanct. Reform efforts aimed at, for example, better targeting of the poor among war victims and heros are unlikely to make much headway. The collective belief in the country's debt to those who participated in the national liberation struggle is deep-seated, at least in the present ruling generation. However, payments under "veterans and war invalids" should eventually depend more on individual circumstances such that the poorest continue to receive the subsidies longer than others. Lastly, if many of those covered by the war-related programs are poor, it is likely that those who similarly suffered on the loosing side are likewise in need of assistance. 
Information is needed to confirm this. If so, help to this group could be targeted on the basis of the same indicators, under a different policy initiative if necessary for political reasons.

\section{CONCLUSIONS}

This paper reviewed the main sources of poverty and vulnerability for households in Vietnam, the government's assistance programs for the poor and vulnerable, and plans for a new umbrella program. In the absence of conclusive evidence on performance, costs and benefits, the paper's assessment approach is descriptive and qualitative. Judgements about what specific interventions do and do not work in Vietnam's safety net must await careful field surveys and rigorous analysis of impacts. In the meantime, it is clear that a better poverty reduction program and safety net would ensue from the strengthening of institutional structures and policies, including: 1) national norms for identifying the poor consistently across regions; 2) survey and other instruments with which to consistently measure and monitor local needs and program performance; 3) integration and coordination between sub-programs with well-defined and universal rules for implementation at the local level; 4) welfare maximizing redistribution of resources across space so that everyone is treated equally regardless of where they reside; and 5) increased resources and attention to helping households and communities deal with covariate risk.

The government's new program, the Hunger Eradication and Poverty Reduction Program (HEPR), does not signify a new policy focus. It subsumes most existing programs, and is primarily an attempt to coordinate policy efforts and resources to increase the safety-net's costeffectiveness and performance. The success of the HEPR depends in large part on it's success in 
transforming the institutional structures and processes which have guided transfer and safety net provision in the past. In particular, progress in the areas listed above could lead to significant improvement in social protection for Vietnam's poor and vulnerable.

While the HEPR concept offers the potential for significant improvements in the safety net, the Government of Vietnam faces a number of difficult challenges. The very principles on which the current highly decentralized, community-based assistance and safety net system is built are threatened by the emerging market economy. In particular, increasing mobility, without which the market system cannot function, dictates a thorough rethinking of the safety net's foundations. Household mobility renders community level identification and targeting of the poor less effective and is likely to make the mobilization of community resources for helping the poor more difficult. The high level of decentralization inhibits the country's ability to provide adequate protection from covariate risks, which, in turn, appear to be on the rise as a result of environmental destruction. Adequately addressing this challenge, and the consequently widening urban-rural and regional inequalities, will require a greater level of risk pooling nationally. Important political hurdles can also be expected in efforts aimed at reallocating resources to better protect Vietnam's poor and vulnerable. 


\section{REFERENCES}

1. For a recent discussion of how households smooth both incomes and consumption in their efforts to mitigate risk see Jonathan Morduch, "Income Smoothing and Consumption Smoothing," Journal of Economic Perspectives, Vol. 9 (1995): 103-114. A review of the theory and empirical literature on whether, and how, the poor insure against risk is given in Harold Alderman and Christina Paxson, "Do the Poor Insure? A Synthesis of the Literature on Risk and Consumption in Developing Countries," Discussion Paper 164, Research Program in Development Studies, Princeton, N.J.: Woodrow Wilson School, 1992.

2. A review of empirical evidence is given in Karla Hoff, "Comment on "Political Economy of Alleviating Poverty: Theory and Institutions," in M. Bruno and B. Plescovic eds., Annual World Bank Conference on Development Economics 1996, Washington, D.C.:World Bank, 1997.

3. Cases whereby central governments are able to redistribute resources across regions so as to better enable poorer areas to enforce central poverty programs and objectives, but are otherwise unable to control local targeting and outcomes, appear to be widespread but understudied. The performance of two specific centrally-mandated and funded, but locallyimplemented safety net programs, are examined in more depth in Anne Case, "The Decentralization of Social Assistance: Evidence from Albania," mimeographed, Research Program in Development Studies, Princeton, N. J.: Princeton University, 1997; and Martin Ravallion, "Reaching Poor Areas in a Federal System," Policy Research Working Paper 1901, Development Research Group, Washington, D.C.: World Bank, 1998. The second examines Argentina's workfare program Trabajar.

4. World Bank, Vietnam: Poverty Assessment and Strategy, Report No. 13442 VN, Washington D.C.: World Bank, 1995.

5. Charlotte Benson, "The Economic Impact of Natural Disasters in Viet Nam," Working Paper 98, London: Overseas Development Institute, 1997.

6. Benson, op. cit.

7. Dominique van de Walle, "Rural Poverty in an Emerging Market Economy: Is Diversification into Non-farm Activities in Rural Vietnam the Solution?," mimeographed, Policy Research Department, Washington, D.C.: World Bank, 1994.

8. World Bank, op. cit.

9. For example, the "risks to livelihood" specific to vulnerable households in a coastal area north of Ho Chi Minh City are described in Doug J. Porter, "Economic Liberalization, Marginality, and the Local State," in B. Kerkvliet and D. Porter, eds., Vietnam's Rural Transformation, Boulder, Co.: Westview Press, 1995. 
10. On coping strategies see Morduch, op. cit., James Scott, The Moral Economy of the Peasant: Rebellion and Subsistence in South East Asia, New Haven: Yale University Press, 1976 and various chapters in Ehtisham Ahmad, Jean Dreze, John Hills, and Amartya Sen, eds., Social Security in Developing Countries, Oxford, U.K.: Clarendon Press, 1991.

11. Jyotsna Jalan and Martin Ravallion, "Are the Poor less Well-Insured? Evidence on Vulnerability to Income Risk in Rural China," Journal of Development Economics, forthcoming, 1998.

12. Benson, op. cit.

13. Van de Walle, op. cit.

14. Donald Cox, James Fetzer and Emmanuel Jimenez, "Private Transfers in Vietnam," pp. 175-199 in D. Dollar, P. Glewwe and J. Litvack eds., Household Welfare and Vietnam's Transition, World Bank Regional and Sectoral Studies, Washington DC: World Bank, 1998.

15. International Labour Office, "Vietnam: Social Protection Development and Training Phase I: Assessment Report," Geneva: ILO, 1996.

16. The ordinance dated August 18, 1994 literally translates as "privileges to revolutionists, fallen soldiers and their families, war invalids, resistance activists, people with meritorious service to the revolution." See Vietnam Ministry of Planning and Investment "National Programme for Hunger Eradication and Poverty Reduction in Vietnam" Hanoi, November 1996.

17. See Lien Huong Tran, "Review of Poverty Measurements, Methods and Poverty programs in Vietnam," Santa Monica, CA: The Rand Corporation, 1995.

18. World Bank, Vietnam: Fiscal Decentralization and the Delivery of Rural Services, Report No. 15745 VN, Washington DC: World Bank, 1996.

19. Tran, op. cit.; World Bank, Vietnam: Fiscal Decentralization and the Delivery of Rural Services, op. cit.

20. MOLISA, "Hunger Elimination and Poverty Reduction Programme Operation Plan for 1998-2000," Hanoi, May 1998.

21. MOLISA, op. cit.

22. Numerous cases of abuse of power by commune officials are documented in Benedict J. Tria Kerkvliet, "Rural Society and State Relations," in Kerkvliet and Porter, op. cit.

23. Abhijit Banerjee and Andrew Newman, "A Dual Economy Model of Modernization and Development," Development Discussion Paper No. 531, Harvard Institute for International Development, Cambridge, MA: Harvard University, 1996, provides a theoretical model which 
predicts such an outcome and in consequence, lower economic development, and rising inequality. The model posits a low productivity, high information traditional (e.g. rural) sector and a high productivity, low information modern (e.g. urban) sector. This results in a tradeoff between an availability of risk insurance in the traditional sector and higher average incomes in the modern sector. The model then predicts that only the rich, who can afford to take risks, and the desperately poor, who have little to lose, will move from rural areas, leading to inefficient and slow modernization. Banerjee and Newman's model does not incorporate the public sector. Yet, the existence of public safety net policies which, as in the Vietnam case, essentially rely on the information content available in the traditional sector and hence reinforce private risk-coping mechanisms, may well exacerbate the model's predicted outcomes.

24. Jyotsna Jalan and Martin Ravallion, "Spatial Poverty Traps," Policy Research Working Papers, Washington, D.C.: World Bank, 1997.

25. Martin Ravallion, Dominique van de Walle, and Madhur Gautam, "Testing a Social Safety Net," Journal of Public Economics, Vol. 57 (1995): 175-199.

26. Benson, op. cit.

27. Benson, op. cit.

28. Benson, op. cit.

29. Benson, op. cit.

30. For a thorough discussion and review of the issues and evidence see Martin Ravallion, "Reaching the Rural Poor through Public Employment: Arguments, Evidence, and Lessons from South Asia," World Bank Research Observer, Vol. 6 (1991): 153-175, and K. Subbarao, Aniruddha Bonnerjee, Jeanine Breathwaite, Soniya Carvalho, Kene Ezemenari, Carol Graham and Alan Thompson, Safety Net Programs and Poverty Reduction: Lessons from Cross-Country Experience, Directions in Development Series, Washington, D.C.: World Bank, 1997. For a case study of such a scheme in China see Zhu Ling and Jiang Zhongyi, "'Yigong-daizhen' in China: A New Experience with Labour-intensive Public Works in Poor Areas," Development Policy Review, Vol. 13 (1995): 349-370.

31. See Tran Thi Van Anh and Nguyen Manh Huan, "Changing Rural Institutions and Social Relations," in Kerkvliet and Porter, op. cit. 